OPEN ACCESS

Edited by:

Gianmarco de Felice,

Università degli Studi

Roma Tre, Italy

Reviewed by:

Theodoros Chris Rousakis,

Democritus University of

Thrace, Greece

Wensu Chen,

Curtin University, Australia

*Correspondence:

Libo Yan

I.yan@tu-braunschweig.de,

libo.yan@wki.fraunhofer.de

Specialty section:

This article was submitted to

Structural Materials,

a section of the journal

Frontiers in Materials

Received: 29 September 2017 Accepted: 27 November 2017 Published: 13 December 2017

Citation:

Yan L, Wang B and Kasal B (2017)

Can Plant-Based Natural Flax

Replace Basalt and E-Glass for

Fiber-Reinforced Polymer Tubular

Energy Absorbers? A Comparative

Study on Quasi-Static Axial Crushing.

Front. Mater. 4:42.

doi: 10.3389/fmats.2017.00042

\section{Can Plant-Based Natural Flax Replace Basalt and E-Glass for Fiber-Reinforced Polymer Tubular Energy Absorbers? A Comparative Study on Quasi-Static Axial Crushing}

\author{
Libo Yan ${ }^{1,2 *}$, Bo Wang ${ }^{1}$ and Bohumil Kasal ${ }^{1,2}$ \\ 'Department of Organic and Wood-Based Construction Materials, Technical University of Braunschweig, Braunschweig, \\ Germany, ${ }^{2}$ Centre for Light and Environmentally-Friendly Structures, Fraunhofer Wilhelm-Klauditz-Institut WKI, \\ Braunschweig, Germany
}

Using plant-based natural fibers to substitute glass fibers as reinforcement of composite materials is of particular interest due to their economic, technical, and environmental significance. One potential application of plant-based natural fiber reinforced polymer (FRP) composites is in automotive engineering as crushable energy absorbers. Current study experimentally investigated and compared the energy absorption efficiency of plant-based natural flax, mineral-based basalt, and glass FRP (GFRP) composite tubular energy absorbers subjected to quasi-static axial crushing. The effects of number of flax fabric layer, the use of foam filler and the type of fiber materials on the crashworthiness characteristics, and energy absorption capacities were discussed. In addition, the failure mechanisms of the hollow and foam-filled flax, basalt, and GFRP tubes in quasi-static axial crushing were analyzed and compared. The test results showed that the energy absorption capabilities of both hollow and foam-filled energy absorbers made of flax were superior to the corresponding energy absorbers made of basalt and were close to energy absorbers made of glass. This study, therefore, indicated that flax fiber has the great potential to be suitable replacement of basalt and glass fibers for crushable energy absorber application.

Keywords: composite materials, natural fibres, crashworthiness, axial crushing, energy absorption

\section{INTRODUCTION}

Because of ever-increasing environmental concern and a high demand to develop sustainable materials, using plant-based natural fibers to substitute glass fibers (e.g., E-glass) of polymer composites has gain popularity (Wambua et al., 2003; Koronis et al., 2013). The benefits of using plant-based fibers are their technical, environmental, and economic significance which are superior to glass fibers to be used in polymer composites (Shah et al., 2013; Yan et al., 2014a). Among dozens of plant-based natural fibers, flax is one of them that have been widely investigated because it offers the best potential combination of low cost, light weight, high strength and stiffness, and annual production yield for structural application (Yan et al., 2014a). One major structural application of plant-based natural fiber-reinforced polymer (FRP) composites may be 
in automotive engineering as crushable energy absorbers. For example, Eshkoor et al. (2013) investigated the crashworthiness characteristics of natural silk epoxy composite tubes. Energy absorption of structures made of composite materials relate to safety in automotive engineering because crashworthiness relates to energy absorption through controlled failure modes that enable the maintenance of a gradual decay in the load profile during energy absorption (Wang et al., 2016). In literature, the effects of different parameters on the crashworthiness behavior and energy absorption capabilities of composite energy absorbers were investigated, i.e., Zhou et al. (2015) investigated the crashworthiness characteristics of carbon fiber-reinforced dualphase epoxy-polyurea hybrid matrix composites, Mozafari et al. (2018) considered double-sided corrugated tubes under axial crushing, and Esnaola et al. (2016) investigated the effect of fiber volume fraction on E-glass/polyester crash structures. To improve energy absorption efficiency of crushable energy absorbers made of composite tubular structures, different foamfiller materials, such as cork core (Sanchez-Saez et al., 2011; Niknejad et al., 2016), aluminum (Fischer, 2016), polyurethane (Yan et al., 2014b), etc., have been used. Literature research indicated that there is no systematic study which compared the crashworthiness characteristics and energy absorption capability of tubular energy absorbers that were made of natural and synthetic fibers (Yan et al., 2015). Therefore, this study evaluated and compared the energy absorption efficiency of plant-based natural flax, mineral-based natural basalt, and synthetic E-glass FRP composite energy absorption tubes to fill the research gap. The effects of tube thickness, using polyurethane-foam (PU) filler, and the type of fiber material on the crashworthiness and energy absorption behavior were discussed. In addition, the failure mechanisms behind the energy absorption of those tubes were analyzed.

\section{EXPERIMENTAL WORKS}

\section{Test Matrix}

In this study, flax FRP (FFRP), basalt FRP (BFRP), and glass FRP (GFRP) composite energy absorption tubes with and without PU filler were constructed and tested under quasi-static axial crushing to investigate their crashworthiness and energy absorption behavior. The test matrix of the specimens used in this study is listed in Table 1. The experimental variables considered included (1) number of fiber layers for FFRP, (2) the use of
PU filler, and (3) the type of fiber materials. In the table, a special code is given for all the types of specimens, e.g., $A-B-C$. The first character $A$ denotes an energy absorption tube with or without foam filler, i.e., $A$ is $P U$ for a tube with foam filler and $A$ is $H$ for a hollow tube. The second character $B$ denotes the number of FRP layers, i.e., $2 \mathrm{~L}$ is for a tube made of 2 -layer FRP, $4 \mathrm{~L}$ is for a tube made of 4-layer FRP, and 6L is for a tube made of 6-layer FRP, respectively. The last character $C$ denotes the type of fiber material, i.e., GFRP, BFRP, and FFRP, respectively. Previous study (Yan et al., 2014c) showed that the use of triggering resulted in a progressive and stable failure of composite tubes during crushing. Therefore, in this study, all the specimens were initiated with triggering, which was a $45^{\circ}$-chamfering around the edge of the tube, as illustrated in Figure 1. The use of triggering can reduce the peak crush load but increase the average crush load, it can also minimize the force variation of the tubular energy absorbers from the average crush force and in turn a more stable progressive failure can be achieved (Yan et al., 2014c).

\section{Materials}

To compare the crashworthiness characteristics of composite tubular energy absorbers made of plant-based natural fiber, mineral-based natural fiber, and synthetic fiber, flax, basalt, and E-glass fibers were selected for the study as one typical representative of these three types of fibers based on their origin. Among all the plant-based natural fibers, flax offers the best combination of low density and cost, high tensile strength and modulus, availability in the market, and large annually producing yielding (Yan et al., 2014a). For mineral-based natural fiber, basalt probably is the only one available in the market, which becomes more and more popular as reinforcing material of polymer composites. This is due to the fact that basalt fiber provides a great balance of cost and mechanical performance when comparing with glass or carbon synthetic fibers (Fiore et al., 2015). For synthetic fiber, E-glass was selected because it is one of the most widely used types in the glass fiber family (e.g., A-glass, C-glass, D-glass, and S-glass) (Yan and Chouw, 2015). The flax fiber used was bidirectional fabric with a plain woven structure and an areal density of $550 \mathrm{~g} / \mathrm{m}^{2}$. The glass fiber was uni-directional fabric with an areal density of $600 \mathrm{~g} / \mathrm{m}^{2}$. The basalt fiber was randomly oriented short monofilament fiber fabric with an areal density of $200 \mathrm{~g} / \mathrm{m}^{2}$. The average diameter of the flax, basalt, and E-glass fiber was 20, 9, and $15 \mu \mathrm{m}$, respectively. The polymer matrix used was epoxy resin and its fast hardener (SP Prime 20 from Gurit). The filler material used was PU foam with a density of $160 \mathrm{~kg} / \mathrm{m}^{3}$, and

TABLE 1 | Test matrix of the composite tubes.

\begin{tabular}{|c|c|c|c|c|c|}
\hline Specimen type & No. of specimens & Inner diameter (mm) & Fiber and fiber reinforced polymer layer & Length (mm) & Polyurethane-foam (PU) filler \\
\hline$H-2 L-F F R P$ & 4 & 64 & 2L-flax & 95 & - \\
\hline$H-4 L-F F R P$ & 4 & 64 & 4L-flax & 95 & - \\
\hline H-6L-FFRP & 4 & 64 & 6L-flax & 95 & - \\
\hline$H-4 L-B F R P$ & 4 & 64 & 4L-basalt & 95 & - \\
\hline$H-4 L-G F R P$ & 4 & 64 & 4L-glass & 95 & - \\
\hline$P U-4 L-F F R P$ & 4 & 64 & 4L-flax & 95 & Yes \\
\hline$P U-4 L-B F R P$ & 4 & 64 & 4L-basalt & 95 & Yes \\
\hline$P U-4 L-G F R P$ & 4 & 64 & 4L-glass & 95 & Yes \\
\hline
\end{tabular}


the diameter of solid cylindrical foam was $64 \mathrm{~mm}$. The fabrication of the FRP tubes was the hand lay-up process following the procedure given in Ref. (Yan et al., 2014c). For 2-layer FFRP, 2-layer BFRP, and 2-layer GFRP, the measured thickness was 3.2, 2.2 , and $2.4 \mathrm{~mm}$, respectively. The tensile properties of the FFRP, BFRP, and GFRP laminates were determined by the flat-coupon tensile test on five laminate specimens and the average results from the five specimens were reported. Figure 2 provides the photos of the flax fabric, basalt fabric mat, and E-glass fabric used for the study. The average tensile strength and modulus of 2-layer FFRP laminate using a Zwick 1474 test machine was $48.2 \mathrm{MPa}$ $(\mathrm{SD}: 1.2 \mathrm{MPa}$ ) and 5.0 $\mathrm{GPa}(\mathrm{SD}: 0.40 \mathrm{GPa})$, respectively. The average tensile strength and modulus of 2-layer GFRP laminate was $441 \mathrm{MPa}(\mathrm{SD}: 18.7 \mathrm{MPa}$ ) and $21.3 \mathrm{GPa}$ (SD: $0.75 \mathrm{GPa}$ ), respectively. The average tensile strength and modulus of 2-layer BFRP laminate was 61.1 MPa (SD: 4.3 MPa) and 5.9 GPa (SD: $0.39 \mathrm{GPa})$, respectively. For the 2-layer FFRP, BFRP, and GFRP composites, the total equivalent structural thickness of the fiber reinforcement in the polymer composites was also measured, which was $2.4,1.4$, and $1.7 \mathrm{~mm}$, respectively. The corresponding fiber layer thickness of flax, basalt, and glass fabric was approximately $1.2,0.7$, and $0.85 \mathrm{~mm}$, respectively. Therefore, the corresponding tensile properties of the FRP composites based on the total equivalent structural thickness of the fiber reinforcement per bearing direction can be calculated. For FFRP, the tensile strength and modulus was 64.2 $\mathrm{MPa}$ and $6.7 \mathrm{GPa}$,

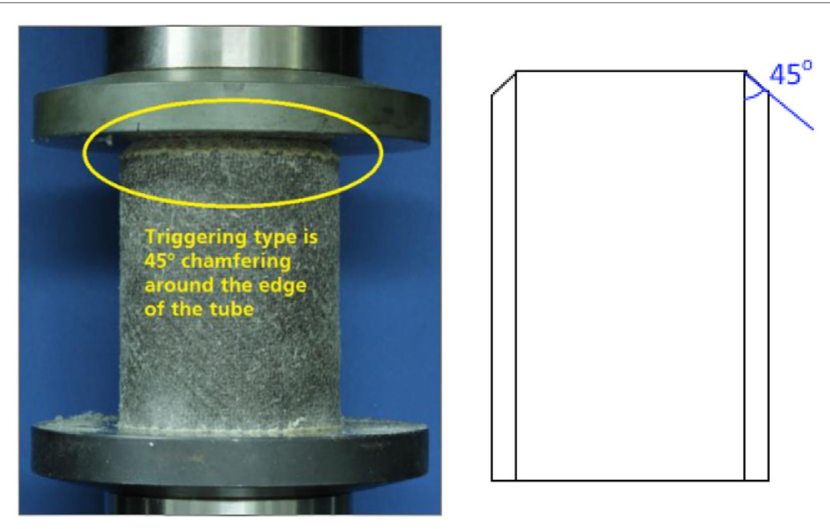

FIGURE 1 | The type of triggering used for the energy absorption tubes. respectively. For BFRP, the tensile strength and modulus was $96 \mathrm{MPa}$ and $9.3 \mathrm{GPa}$, respectively. For GFRP, the tensile strength and modulus was $622.6 \mathrm{MPa}$ and $30.1 \mathrm{GPa}$, respectively.

\section{Test Instrumentation}

Quasi-static axial compressive tests were conducted to investigate the crashworthiness and energy absorption behavior of these composite tubes using the Zwick 1474 test machine. The crosshead speed of the testing used was $15 \mathrm{~mm} / \mathrm{min}$. Before the testing of the composite tubes, the foam was tested first. The axial load vs. displacement curve and the progressive compression process of the PU foam are illustrated in Figures $\mathbf{3}$ and $\mathbf{4}$, respectively. As shown in Figure 3, the response of foam in axial compression can be characterized in three stages: an initial elastic stage, corresponding to Figure $4 \mathrm{~A}$, a plateau stage, corresponding to Figures $4 \mathbf{B}, \mathbf{C}$, and the densification stage, corresponding to Figure 4D.

\section{Crashworthiness Behavior}

In current study, the considered crashworthiness and energy absorption parameters of the tubular energy absorbers are:

- peak crush load $P_{\max }$, which is the maximum initial load needed to initiate the crushing of the energy absorber. In crashworthiness design, it is desirable to have a low value of $P_{\max }$ to prevent the vehicle occupants from injuries and reduce damage due to high reaction forces.

- absorbed crush energy AE, which is the area under the load vs. displacement curve. It is used to evaluate the capacity of a tubular energy absorber to dissipate crushing energy through deformation.

- specific absorbed energy (SAE), which is the AE per unit mass of the specimen. SAE is used to facilitate the evaluation of energy absorption capacity of tubular energy absorbers made of different materials.

- average crush load $P_{\text {avg, }}$ which is the ratio of $\mathrm{AE}$ in the post-crushing zone to the post-crushing displacement. The $P_{\text {avg }}$ is the average crushing force resisted by the tubular energy absorbers during the post-crushing zone.

- crush force efficiency CFE, which the ratio of average load to the peak load. The CFE is directly related to the deceleration that will be experienced by the vehicle occupants in the event of a crash. It is desirable to have the value of CFE close to unity for good energy absorption (Yan et al., 2014c).

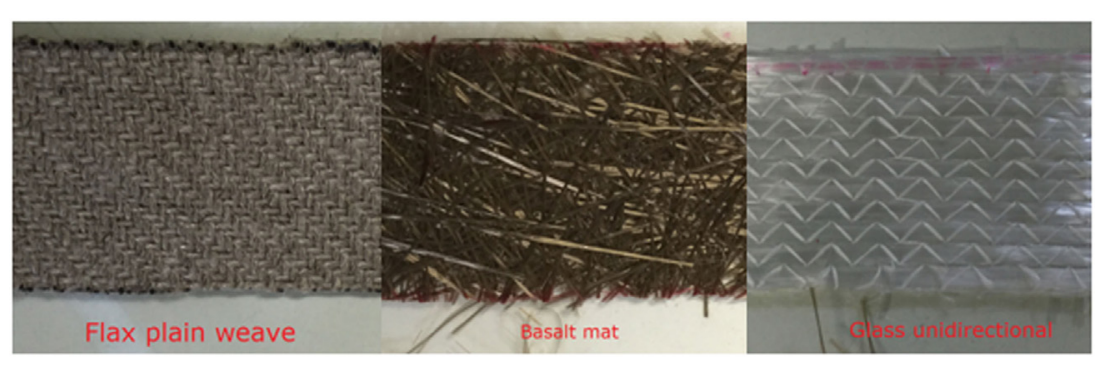

FIGURE 2 | Photo of flax, basalt, and E-glass fabrics. 


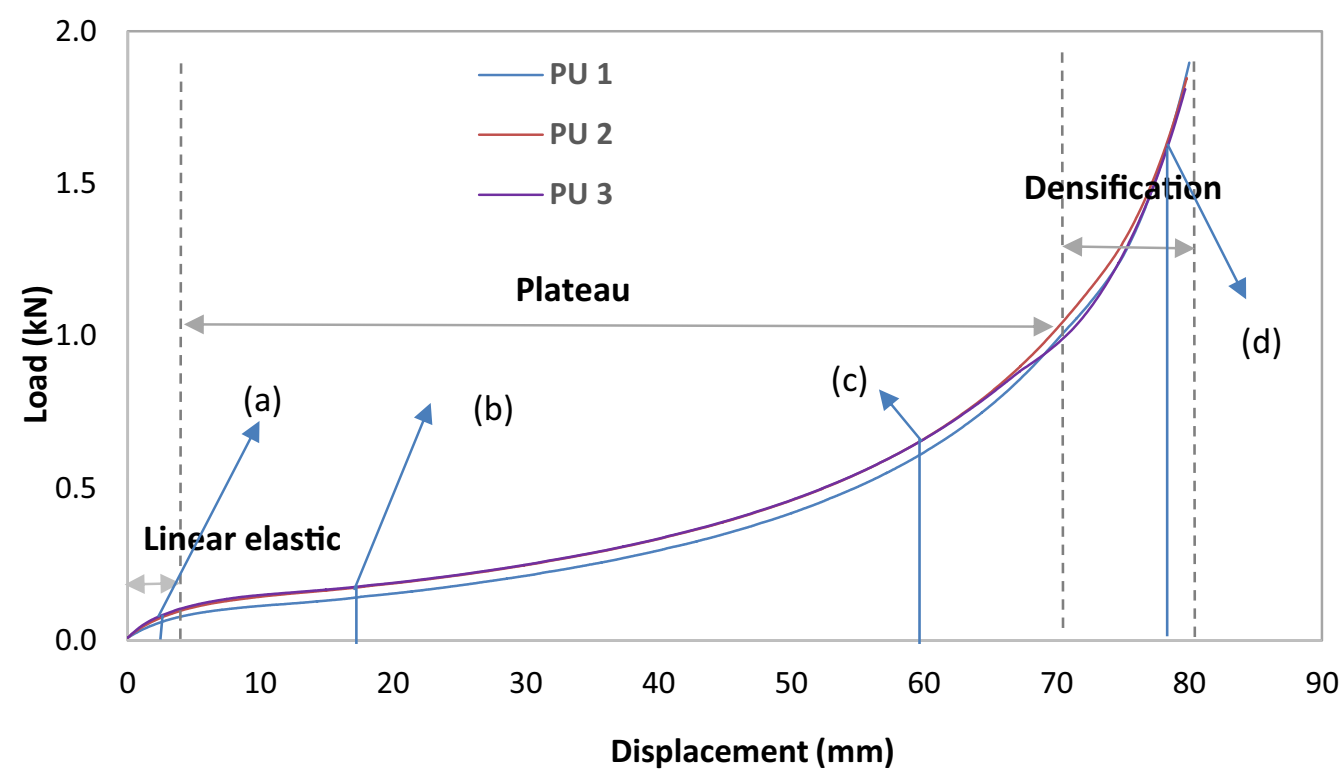

FIGURE 3 | Typical axial compression load vs. displacement curve of foam filler.

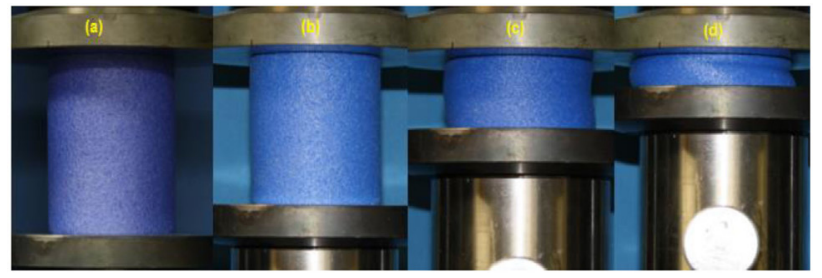

FIGURE 4 | The progressive compression process of the foam filler.

More details about how to define and calculate these parameters were introduced in Yan and Chouw (2013). Overall, a tubular energy absorber shows good crashworthiness and energy absorption behavior if the absorber has low initial $P_{\max }$, high $\mathrm{AE}$, and high SEA.

\section{RESULTS AND DISCUSSIONS}

According to test results, the effects of number of flax fabric layers, the type of fiber materials, and the use of PU filler on the crashworthiness characteristics of these composite tubes are discussed and compared. In addition, the failure mechanisms of hollow and foam-filled tubes were discussed.

\section{Effect of Flax Fabric Layers}

Table 2 lists the average values of the specimens under axial crushing test. The average results obtained from testing on four specimens for each type of tubular energy absorber. The testing results shown that the $\mathrm{SD}$ of these crashworthiness parameters was relatively small, i.e., less than $10 \%$ variation and, therefore, the average values were used for the discussion. As listed in Table 2, the peak load, average crushing load, total absorber energy of the
TABLE 2 | Average results of different composite tubes in quasi-static axial compression.

\begin{tabular}{lcrrrrrr}
\hline $\begin{array}{l}\text { Specimen } \\
\text { type }\end{array}$ & $\begin{array}{c}\text { Thickness } \\
(\mathbf{m m})\end{array}$ & Mass (g) & $\begin{array}{c}\boldsymbol{P}_{\max } \\
\mathbf{( k N )}\end{array}$ & $\begin{array}{l}\mathbf{P}_{\text {avg }} \\
\mathbf{( k N )}\end{array}$ & $\mathbf{A E}(\mathbf{J})$ & $\begin{array}{c}\text { Specific } \\
\text { absorbed } \\
\text { energy (J/g) }\end{array}$ & CFE \\
\hline H-2L-FFRP & 2.7 & 96.4 & 31.1 & 17.7 & 1,418 & 14.7 & 0.57 \\
H-4L-FFRP & 5.4 & 130.9 & 60.4 & 40.1 & 3,469 & 26.5 & 0.68 \\
H-6L-FFRP & 7.9 & 153.3 & 93.5 & 61.7 & 4,690 & 30.6 & 0.66 \\
H-4L-BFRP & 3.8 & 95.7 & 42.7 & 27.4 & 2,192 & 22.9 & 0.64 \\
H-4L-GFRP & 4.6 & 90.6 & 59.7 & 35.8 & 2,865 & 31.6 & 0.60 \\
PU-4L-FFRP & 5.4 & 131.0 & 67.8 & 50.2 & 3,838 & 29.3 & 0.74 \\
PU-4L-BFRP & 4.1 & 96.5 & 44.4 & 31.1 & 2,326 & 24.1 & 0.70 \\
PU-4L-GFRP & 4.6 & 89.8 & 57.1 & 47.5 & 3,403 & 37.9 & 0.84 \\
\hline
\end{tabular}

hollow FFRP tubes increased remarkably due to an increase of the flax fabric layers from two to six. The enhancement in the peak and average loads was almost proportional to the addition of the number of the fabric layers. The effect of fabric layer on SAE and CFE is illustrated in Figure 5. Figure 5A shows that an increase in fabric layer resulted in an increase in the SAE; however, the increase in the SAE from four to six layers was less pronounced than that when the number of the flax fabric layer increased from two to four. For the CFE value, there was an increase when the number of flax fabric layer increased from two to four. The further increase of flax fabric layer from four to six even slightly reduced the CFE of the hollow FFRP tubes. The data here imply that critical thickness of FFRP composite tube may exist to have an optimized crush force efficiency.

Figure 6 shows the effect of flax fabric layer on typical axial crush load vs. crush displacement responses of hollow tubes. As can be seen, all the curves increased sharply with the load up to the initial peak crush load corresponded to a small crushing deformation around $3-5 \mathrm{~mm}$, indicating the trigger of the 

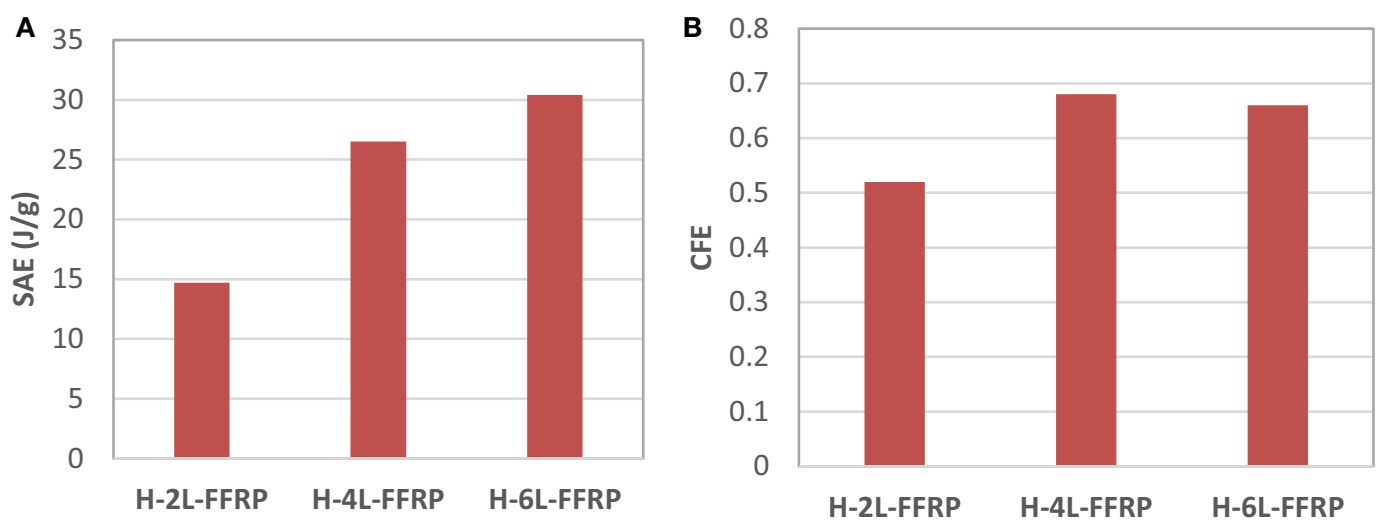

FIGURE 5 | Effect of number of flax fabric layers on specific absorbed energy (SAE) (A) and CFE (B) of hollow flax FRP (FFRP) tubes.

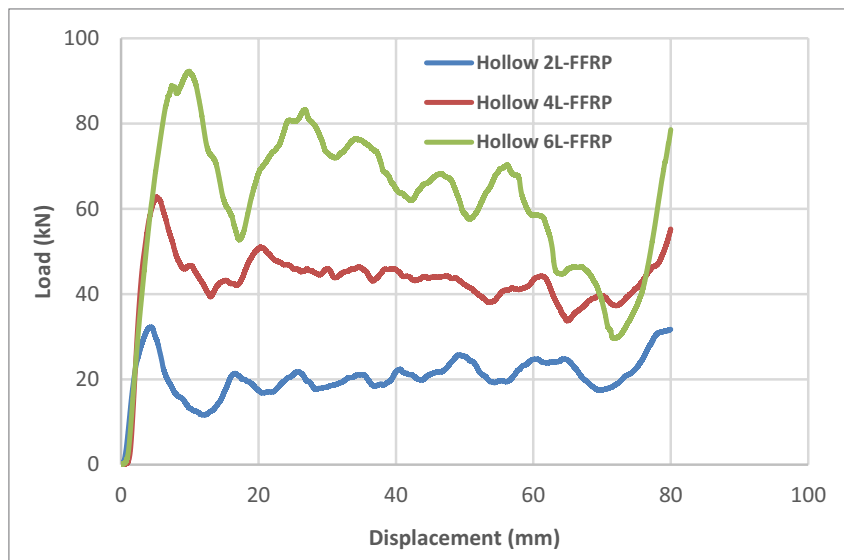

FIGURE 6 | Typical axial load vs. displacement curves of two-, four-, and six-layer hollow flax FRP (FFRP) tubes.

crushing of the tubes. Then, the curves decreased rapidly with a reduction of the crushing load and followed by a steady state crushing process. The rapid decrease after the reached the peak load corresponded to the initiation of the fracture of the tubes and the steady state crushing corresponded to the progressive crushing of the tubes.

\section{Effect of PU Filler}

Table 2 also shows that the use of PU filler had a positive effect on the average crushing load, total absorbed energy, specific absorber energy, and the crush force efficiency for all the 4-layer flax, basalt and GFRP composite tubes. For the average crushing load, the increase due to PU filler for hollow flax, basalt, and glass was 25.2 (from 40.1 to $50.2 \mathrm{kN}$ ), 13.5 (from 27.4 to $31.1 \mathrm{kN}$ ), and $35.7 \%$ (from 35.8 to $47.5 \mathrm{kN}$ ), respectively. For the average total absorber energy, the increase due to PU filler for hollow FFRP, BFRP, and GFRP tubes was 10.6 (from 3,469 to 3,838 J), 6.1 (from 2,192 to $2,326 \mathrm{~J}$ ), and $18.8 \%$ (from 2,865 to $3,403 \mathrm{~J}$ ), respectively. Figure 7 shows the effect of foam filler on the average SAE and average CFE of 4-layer flax, basalt and GFRP composite tubes.
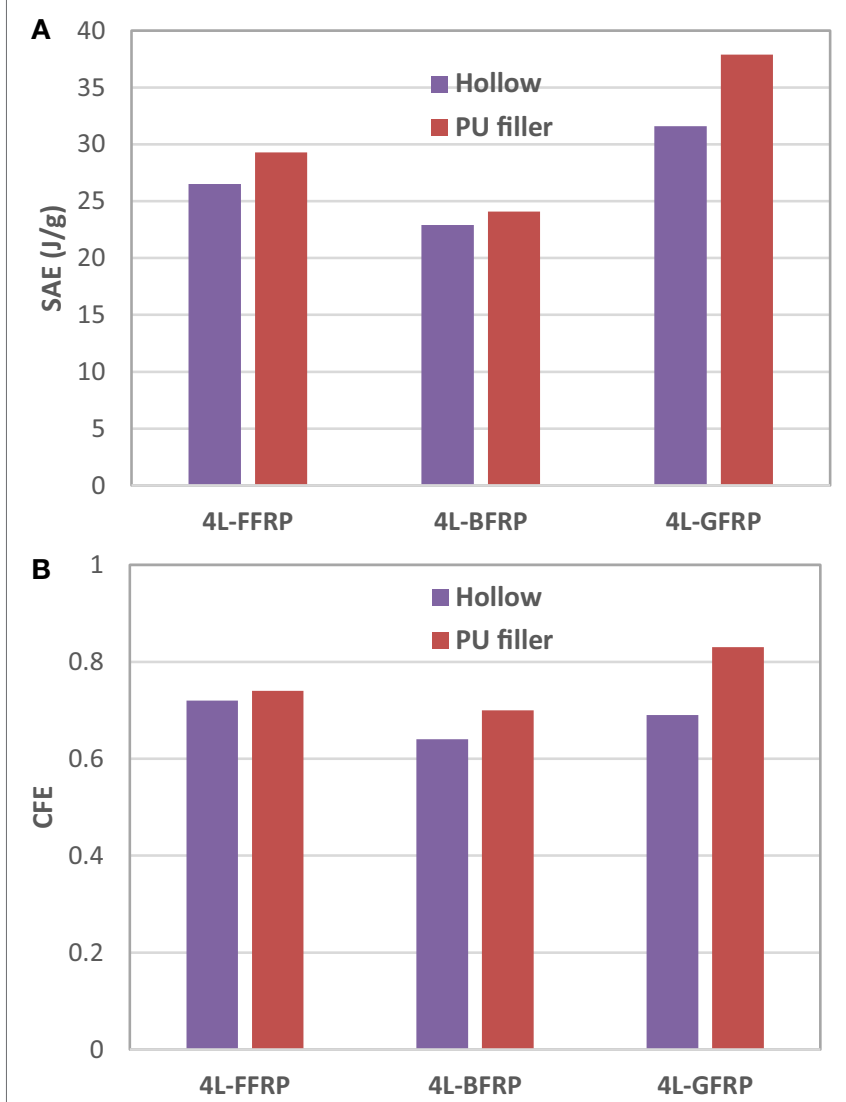

FIGURE 7 | Effect of foam filler on (A) specific absorbed energy (SAE) and (B) CFE of 4-layer flax FRP (FFRP), 4-layer basalt FRP (BFRP), and 4-layer glass FRP (GFRP) tubes.

As expected, the use of foam filler increased the SAE and CFE of all the FFRP, BFRP, and GFRP tubes. The corresponding increase in the SAE of FFRP, BFRP, and GFRP tubes was 10.5 (from 26.5 to $29.3 \mathrm{~J} / \mathrm{g}$ ), 5.2 (from 22.9 to $24.1 \mathrm{~J} / \mathrm{g}$ ), and $18.9 \%$ (from 31.6 to $37.9 \mathrm{~J} / \mathrm{g}$ ), respectively. It is believed that the addition of PU foam filler resulted in a more stable and progressive fracture of 
the composite tubes due to the foam-filler effect. During the axial crushing, the foam deformed laterally and provided circumferential pressure to the inner surface of the energy absorption tube and generated interaction between the tube and the PU foam filler, where these two components worked together to resist the crushing and eventually improved the average load, AE and the SAE.

Figures 8-10 shows the effect of PU foam filler on the typical axial crushing load vs. crushing displacement of FFRP, BFRP, and GFRP composite tubes, respectively. From Figures 8-10, it can be observed that both hollow and the foam-filled FFRP, BFRP, and GFRP specimens exhibited the progressive and relatively stable crushing behavior. The use of the foam filler did not show obvious effect on the stiffness of the composite tubes, as defined from the slope of the elastic curves before reached the initial peak load. From the figures, it can be seen that the effect of the foam filler mainly worked at the latter part of the crushing displacement range (i.e., after the displacement of $30 \mathrm{~mm}$ ), where the crush loads of all the filled FRP tubes were typically larger than that of the corresponding hollow specimens. Thus, the energy absorption capacity of the composite tubes was increased due to the increase of the crush load after the addition of foam filler.

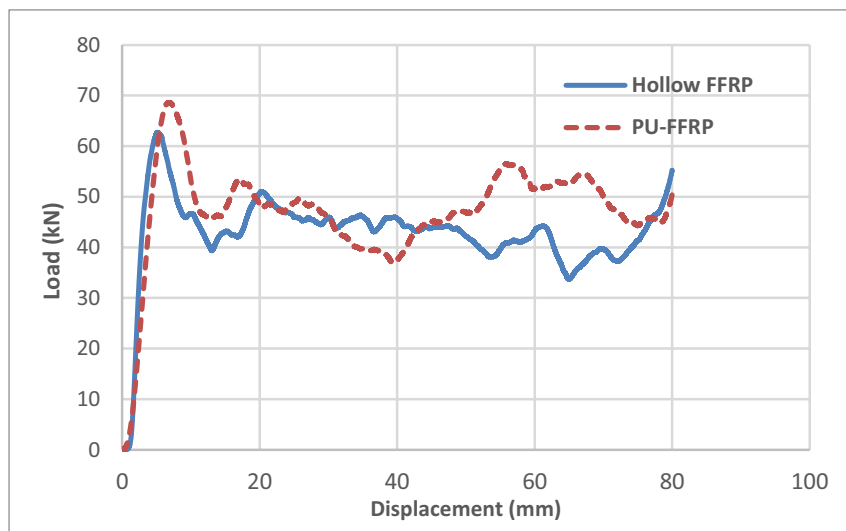

FIGURE 8 | Axial crushing load vs. displacement of hollow and foam-filled flax FRP (FFRP) tubes.

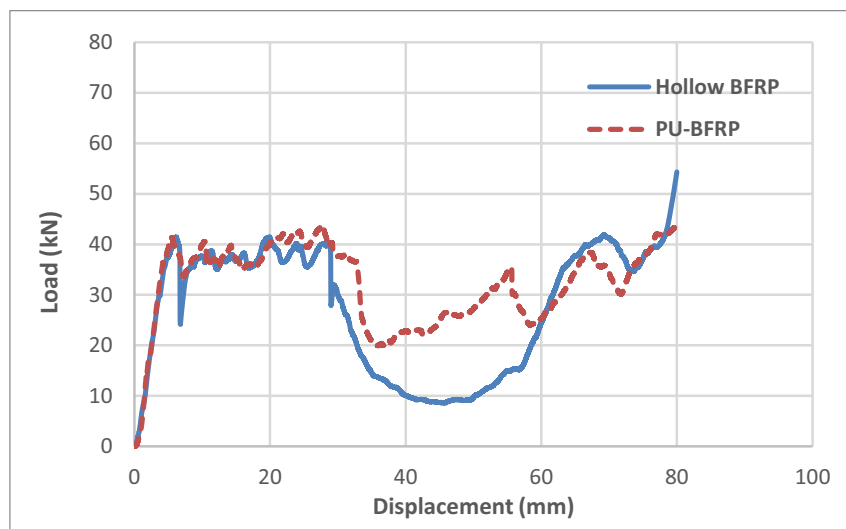

FIGURE 9 | Axial crushing load vs. displacement of hollow and foam-filled basalt FRP (BFRP) tubes.
From Figures 8-10 it can be seen that there was a quick drop in the load after the initial peak for FFRP tube only. It can be interpreted by the fact that the compressive strength of the FFRP composites was much lower compared with the BFRP and GFRP composites, thus, more fiber micro-cracks generated after the initial peak load due to the lower load resistance of the FFRP tube under the axial crushing. As introduced before, for crashworthiness safety design, it is desirable to have an energy absorber with a low initial peak crush load, while the use of foam filler increased the initial peak crush load in some cases (e.g., Figure 8); therefore, future study focusing on geometry and material optimization of foam filler for those composite energy absorbers is needed.

\section{Effect of Fiber Type}

As discussed in previous study (Yan et al., 2014b), the use of SAE is essential when comparing the energy absorption behavior of crushable energy absorbers fabricated by different materials. Using SAE to compare the energy absorption capability of

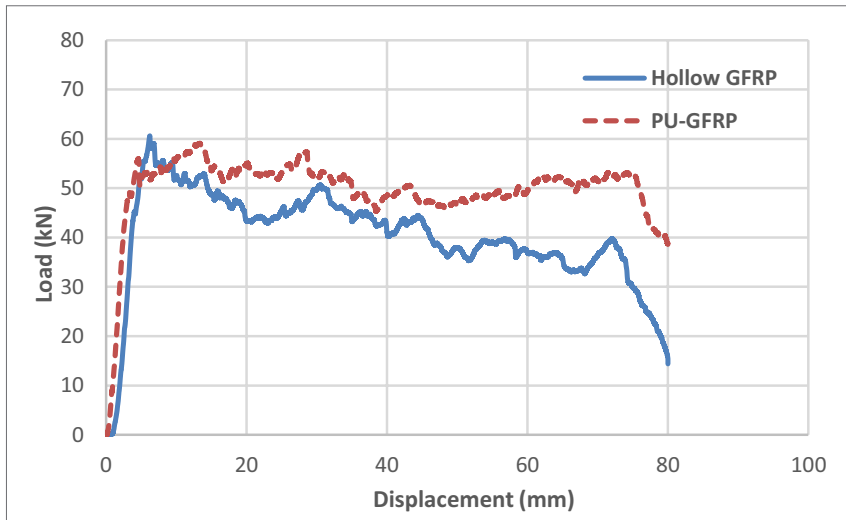

FIGURE 10 | Axial crushing load vs. displacement of hollow and foam-filled glass FRP (GFRP) tubes.

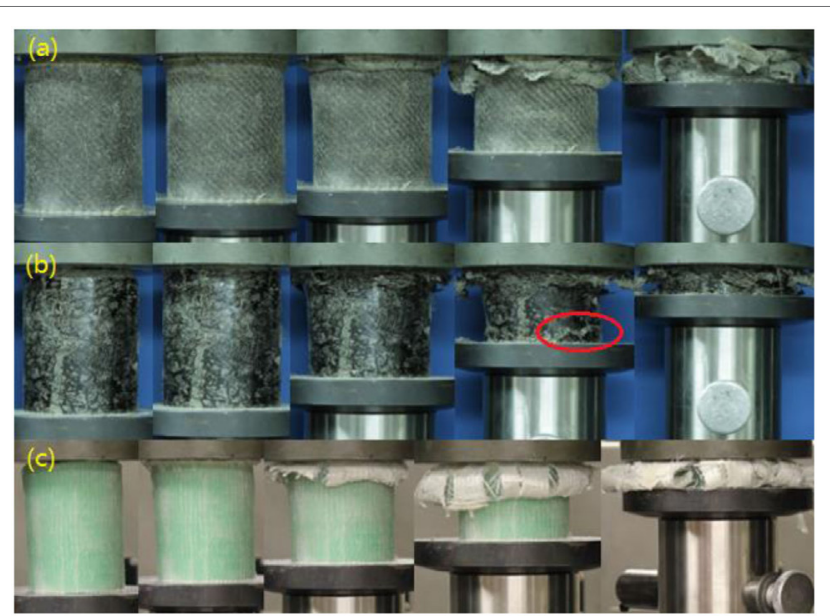

FIGURE 11 | Typical progressive crushing processes of foam-filled fiber reinforced polymer tubes: (A) flax, (B) basalt, and (C) glass. 
crushable energy absorbers fabricated by different structures and materials (i.e., metallic, composites, and alloys) is a widely accepted criterion in crashworthiness design of vehicle in the past decades (Thornton, 1979; Mamalis et al., 1997; Carruthers et al., 1998; Lu and Xu, 2003; Tarlochan and Ramesh, 2012; Yan and Chouw, 2015). Generally, the larger the value of the SAE, the more efficient the energy absorber will be. Table 2 shows that for FFRP, BFRP, and GFRP composite hollow tubes with the same number of fabric layers, and same height and inner diameter of the tube, their SAE values were $26.5,22.9$, and $31.6 \mathrm{~J} / \mathrm{g}$, respectively. For the foam-filled FFRP, BFRP, and GFRP tubes with the same number of fiber fabric layers and same height and inner diameter of the tube and same dimension of the foam filler,

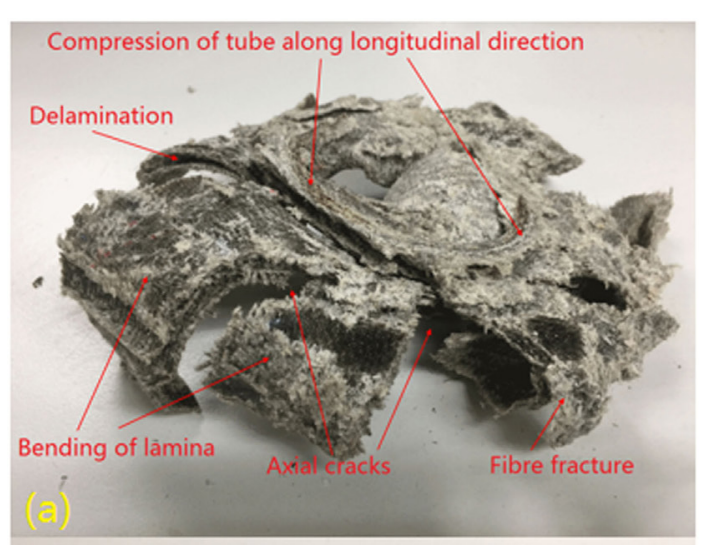

Compression of tube along longitudinal direction
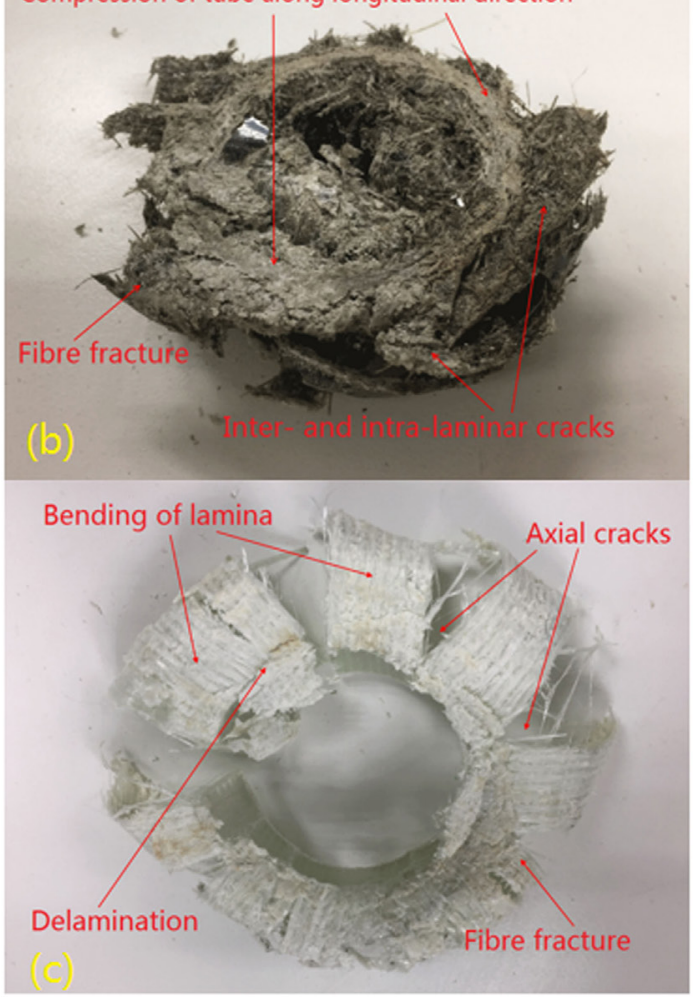

FIGURE 12 | Typical failure modes of hollow fiber reinforced polymer tubes: (A) flax, (B) basalt, and (C) glass. their SAE values were 29.3, 24.1, and $37.9 \mathrm{~J} / \mathrm{g}$, respectively. The comparison of the values here implied that the energy absorption capability of both hollow and filled plant-based natural FFRP energy absorbers were larger (i.e., 13.6 and 17.7\%, respectively, for hollow and foam-filled tubes) than the corresponding

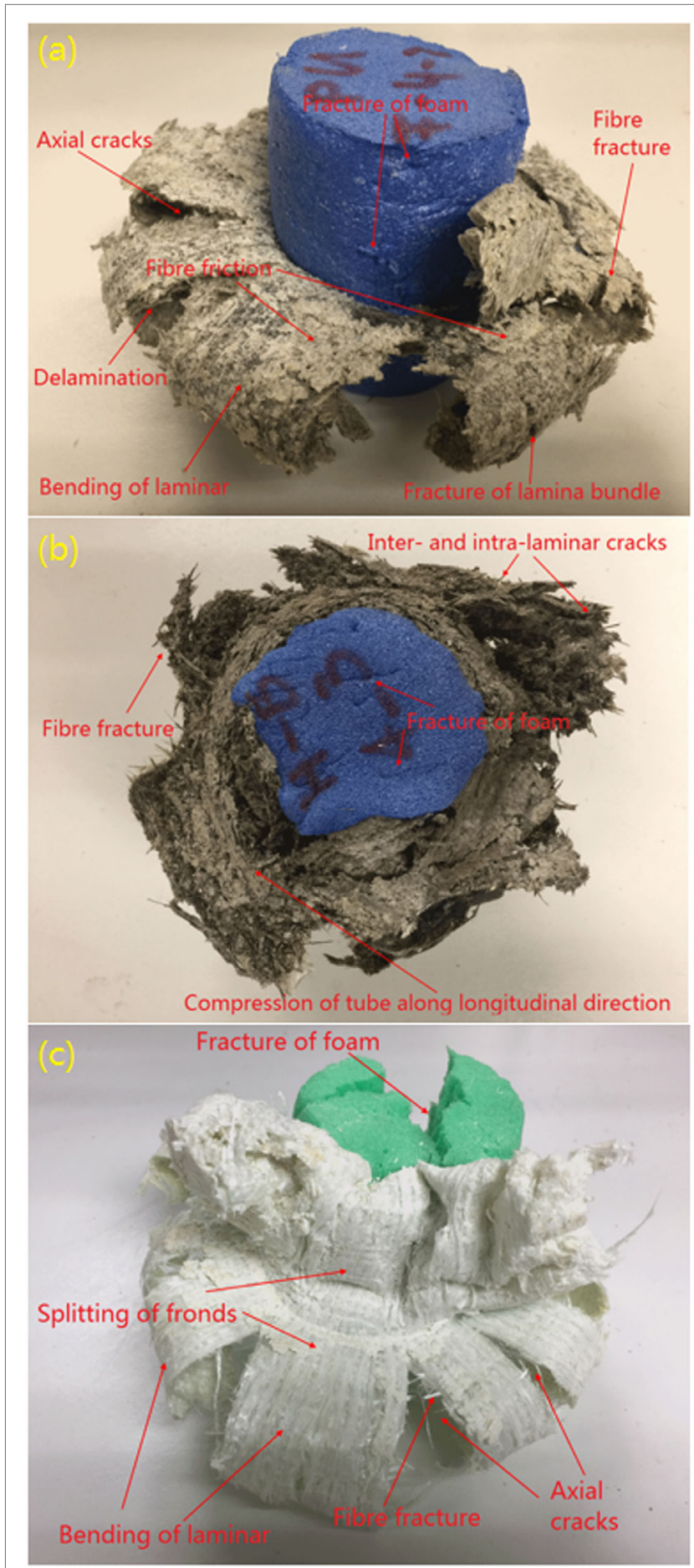

FIGURE 13 | Typical failure modes of foam-filled fiber reinforced polymer tubes: (A) flax, (B) basalt, and (C) glass. 
mineral-based natural BFRP energy absorbers, those of both hollow and filled FFRP energy absorbers were slightly lower (i.e., 16.1 and $22.7 \%$, respectively, for hollow and foam-filled tubes) than the corresponding synthetic GFRP energy absorbers. However, it should be pointed out that the SAE value $(29.3 \mathrm{~J} / \mathrm{g})$ of foam-filled FFRP tube was very close to (i.e., a difference of 7.2\%) that of the hollow GFRP tube $(31.6 \mathrm{~J} / \mathrm{g})$, although the average tensile strength and modulus of the FFRP composites were significantly lower compared with those of GFRP composites obtained from flat-coupon tensile test, as listed in Section "Materials." Thus, with proper tailor and design, e.g., optimization of geometry and use of foam filler, it is achievable to make the energy absorption capacity of energy absorbers made of plant-based natural flax fiber to be comparable to those made of synthetic E-glass fiber.

\section{Crushing Process and Failure Modes}

Figure 11 shows the typical progressive crushing of foam-filled FFRP, BFRP, and GFRP tubes under axial crushing. Photographs at different crushing stages were captured to show the deformation and crack propagation of the composite tubes. As illustrated, the existence of the triggering (i.e., $45^{\circ}$ chamfering around the edge of the tube) caused all the FFRP, BFRP, and GFRP tubes having an initial trigger of crushing started from the upper end of the tube because of the high localized stress concentration. When the applied load made the concentrated stress which exceeded the theoretical cohesive strength of the FRP material, the composite tube started to crush by the formation and propagation of cracks. Next, the further propagation of the cracks occurred along the longitudinal direction of the tubes (especially in the cases of GFRP and FFRP tubes) caused the formation of the fronds outwards. Here, it should be pointed out that for the BFRP tube, during the steady state of the crushing process, cracks in the tube circumferential direction (as highlighted with red oval i.n Figure 11) were observed at the lower end of the tube, which resulted in the sudden drop of the load in the load-displacement curve displayed in Figure 9.

Figure 12 shows the typical failure modes of the hollow FFRP, BFRP, and GFRP tubes under axial crushing. It is clear that the major failure mechanisms of hollow FFRP tube include compression of the tube along the tube longitudinal direction, axial cracks in the tube longitudinal direction, bending of fronds and laminar bundles, fiber fracture, and delamination in the laminar, which all contributed to the energy absorption of the FFRP tube during the crushing. For the hollow BFRP tube, the main failure mechanisms were compression of the tube along the tube longitudinal direction, fiber fracture and inter- and intra-laminar cracks. Bending of fronds and axial cracks were not observed obviously, which might be attributed to the structure of the fibers in the composite, as basalt fibers were randomly oriented short fiber mat while flax fibers were bidirectional fabrics, in which the flax fiber reinforcement in the warp direction was parallel to the longitudinal direction of the tube. For hollow GFRP tube, the failure mechanisms were quite similar to those of hollow FFRP tube; however, there was one distinct difference, namely, the failure of compression of the tube along longitudinal direction was not observed in the GFRP tube. This might be attributed to the uni-directional structure of the glass fibers in the composite. In the GFRP tube, the main glass fiber reinforcement was along the longitudinal of the tube. In the hoop direction of the tube, only very slight amount of glass fiber yarns existed to the glass fibers in the tube longitudinal direction.

Figure 13 shows the typical failure modes of the foam-filled FFRP, BFRP, and GFRP tubes under axial crushing. For all the three different types of composite tubes, fracture of the foam filler was observed, which can also contribute to the energy absorption of the composite tubes in the crushing. Compared with the failure modes of foam-filled FFRP tube and its hollow tube, it is clear that except for the typical failure mechanisms observed in the hollow tube, noticeable fiber friction failure (with the inner foam) was observed in the foam-filled tube, which might be used to explain the larger SAE and AE values of the foam-filled tube due to the addition of foam filler, as fiber friction also gave great contribution to the total energy absorption and the specific absorbed energy (SAE) of the tube. In the case of GFRP tube, compared with its hollow tube, except for the fracture of the foam, the foam-filled GFRP tube showed additional failure mode

TABLE 3 | Comparison between plant-based flax fiber and E-glass (Le Duigou et al., 2011; Shah et al., 2013; Yan et al., 2014a; Fiore et al., 2015) (BasaltToday, 2017; Available from: http://basalt.today/about-en/).

\begin{tabular}{|c|c|c|c|c|}
\hline & Properties & Flax & E-glass & Basalt \\
\hline \multirow[t]{3}{*}{ Economy } & Annual global production (million tonnes) & $0.5-1.5$ & 4.0 & 1.0 \\
\hline & Used for fiber reinforced polymer in EU (tonnes) & Low $(25,000)$ & High $(600,000)$ & Low $(100,000)$ \\
\hline & Cost of raw fiber (€) & Low $(0.5-1.5)$ & Moderate (2.0-3.5) & Moderate (2.0-3.5) \\
\hline \multirow[t]{7}{*}{ Technical } & Density $\left(\mathrm{g} \cdot \mathrm{cm}^{-3}\right)$ & $\operatorname{Low}(\sim 1.40)$ & High $(\sim 2.50)$ & High ( 2.80) \\
\hline & Tensile stiffness (GPa) & Moderate (27-103) & Moderate (73) & Moderate (89) \\
\hline & Tensile strength (GPa) & Low $(0.4-2.0)$ & Moderate (2.0-3.5) & Moderate (2.8) \\
\hline & Tensile failure strain (\%) & Low (1.2-3.3) & Low (2.5) & Low (3.0) \\
\hline & Specific tensile stiffness $\left(\mathrm{GPa} / \mathrm{g} \cdot \mathrm{cm}^{-3}\right)$ & Moderate (19-73) & Moderate (27) & Moderate (31) \\
\hline & Specific tensile strength $\left(\mathrm{GPa} / \mathrm{g} \cdot \mathrm{cm}^{-3}\right)$ & Moderate (0.3-1.4) & Moderate (0.7-1.3) & Moderate (1.0) \\
\hline & Abrasive to machines & No & Yes & Yes \\
\hline \multirow[t]{5}{*}{ Ecological } & Energy consumption (MJ/kg of fiber) & Low (11.4) & Moderate (54.7) & Moderate (54.7) \\
\hline & Renewable source & Yes & No & No \\
\hline & Recyclable & Yes & Partly & Partly \\
\hline & Biodegradable & Yes & No & No \\
\hline & Toxic (upon inhalation) & No & Yes & Yes \\
\hline
\end{tabular}




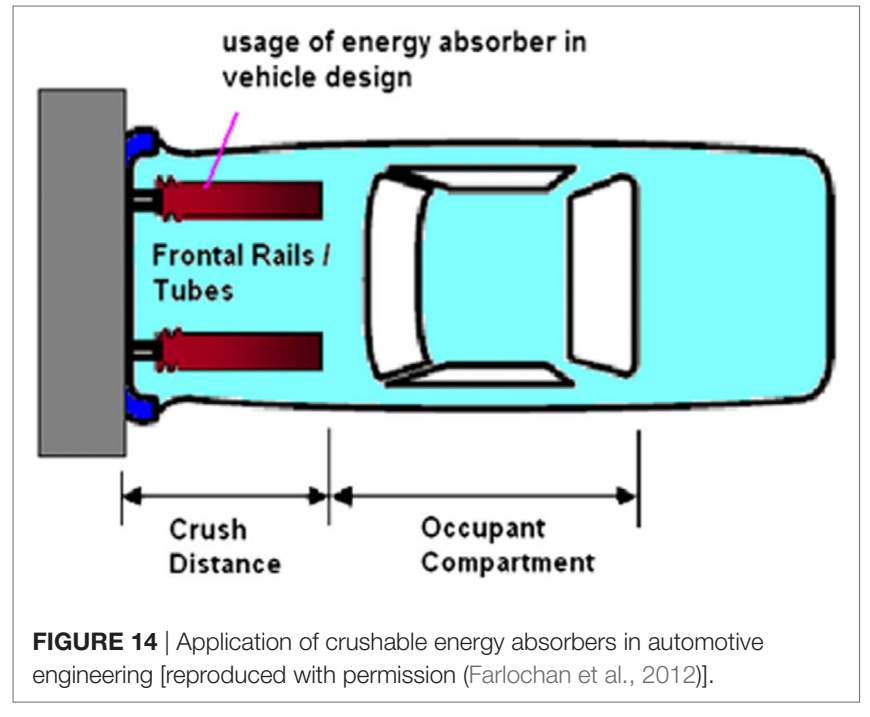

of splaying and splitting of the fronds. For BFRP tube, the failure modes of the hollow and foam-filled tubes were quite similar, but additional fracture of foam filler and tight restraint of the foam filler by the outer BFRP component were observed in the foam-filled tube.

It should be pointed out here that in the quasi-static crushing, the composite tubes were tested at a constant speed and which was quite helpful to identify the fracture mechanisms of the composite tubes, it was not a true simulation of a crash condition, thus, future study should focus on the dynamic impact tests of considering stress rate sensitivity of those energy absorption tubes made of different composite materials to have true simulation of crash.

\section{Comparison between Plant-Based Flax and Synthetic E-Glass}

As listed in Table 3, the plant-based natural flax fibers provide various economical, technical, and ecological significances when comparing mineral-based natural basalt and synthetic E-glass fibers as reinforcing materials to be used in polymer composites. Compared with basalt and E-glass fibers, flax fibers are relative abundant, cheaper, lighter (lower density), biodegradable, and non-abrasive. In addition, the specific tensile properties of flax fibers are comparable to those of basalt and E-glass fibers. Furthermore, the flax fiber and its composites have great opportunities for development and market capture

\section{REFERENCES}

Carruthers, J. J., Kettle, A. P., and Robinson, A. M. (1998). Energy absorption capability and crashworthiness of composite material structures: a review. App. Mech. Rev. 51, 635-649. doi:10.1115/1.3100758

Eshkoor, R. A., Oshkovr, S. A., Sulong, A. B., Zulkifli, R., and Azhari, C. H. (2013). Effect of trigger configuration on the crashworthiness characteristics of natural silk epoxy composite tubes. Compos. B 55, 5-10. doi:10.1016/j.compositesb. 2013.05.022

Esnaola, A., Tena, I., Aurrekoetxea, J., Galego, I., and Ulacia, I. (2016). Effect of fibre volume fraction on energy absorption capabilities of E-glass/polyester automotive crash structures. Compos. B 85, 1-7. doi:10.1016/j.compositesb.2015.09.007 as Table 3 showed that the current amount of flax fibers used for FRP in European Union was still very low (Shah et al., 2013; Yan et al., 2014a).

\section{CONCLUSION}

In this study, plant-based natural FFRP, mineral-based natural BFRP, and synthetic GFRP energy absorption tubes with and without foam filler were manufactured by hand lay-up process and their crashworthiness characteristics were investigated experimentally by a quasi-static axial compression. The effects of number of flax fabric layers, the addition of foam filler and fiber materials on the energy absorption capabilities of these composite tubes were discussed. This study reveals that:

(1) The increase of the number of the flax fabric layers resulted in the increase in the peak crush load, average crush load, total energy absorption, specific energy absorption of the tubular energy absorbers in the quasi-static axial crushing.

(2) The addition of PU foam filler increased the average load, the total energy absorption, specific energy absorption, and crush force efficiency of FFRP, BFRP, and GFRP energy absorbers effectively. The use of foam filler may either increase or reduce the peak crush load of the composite energy absorbers.

(3) For both hollow and foam-filled tubular energy absorbers, the SAE of these tubes made of flax were larger than those made of basalt, and the SAE of these tubes made of flax were slightly less than those made of glass. However, the SAE of foam-filled FFRP tube was comparable to those of hollow GFRP tubes, although the tensile strength and modulus of the FFRP laminates were significantly lower compared with those of GFRP.

In general, the plant-based natural flax fiber shows great potential to be suitable replacement of mineral-based basalt and synthetic E-glass fibers for crushable energy absorber application (Figure 14). Further studies focusing on geometry optimization of foam filler and dynamic impact tests will be required.

\section{AUTHOR CONTRIBUTIONS}

LY and BK managed the project, LY designed the experimental works and wrote the manuscript, BK provided constructive comments to the manuscript. BW conducted the experimental works and helped in the data analysis.

Farlochan, F., Ramesh, S., and Harpreet, S. (2012). Advanced composite sandwich structure design for energy absorption applications: blast protection and crashworthiness. Compos. B 43, 2198-2208. doi:10.1016/j.compositesb. 2012.02.025

Fiore, V., Scalici, T., Di Bella, G., and Valenza, A. (2015). A review on basalt fibre and its composites. Compos. B 74, 74-94. doi:10.1016/j.compositesb. 2014.12.034

Fischer, S. F. (2016). Energy absorption efficiency of open-cell pure aluminium foams. Matter. Lett. 184, 208-210. doi:10.1016/j.matlet.2016.08.061

Koronis, G., Silva, A., and Fontul, M. (2013). Green composites: a review of adequate materials for automotive applications. Compos. B 44, 120-127. doi:10.1016/j. compositesb.2012.07.004 
Le Duigou, A., Davies, P., and Baley, C. (2011). Environmental impact analysis of the production of flax fibres to be used as composite material reinforcement. J. Bio. Mater. Bioenergy 5, 1-13. doi:10.1166/jbmb.2011.1116

Lu, G. X., and Xu, T. X. (2003). Energy Absorption of Structures and Materials. Cambridge: Woodhead Publishing Limited, 1-23.

Mamalis, A. G., Robinson, M., Manolakos, D. E., Demosthenous, A. G., Ioannidis, M. B., and Carruthers, J. (1997). Review: crashworthy capability of composite material structures. Compos. Struct. 37, 109-134. doi:10.1016/ S0263-8223(97)80005-0

Mozafari, H., Lin, S. M., Tsui, C. P., and Gu, L. X. (2018). Controllable energy absorption of double sided corrugated tubes under axial crushing. Compos. $B$ 134, 9-17. doi:10.1016/j.compositesb.2017.09.042

Niknejad, A., Moradi, A., and Beheshti, N. (2016). Indentation experiments on novel sandwich composite tubes. Matter. Lett. 179, 142-145. doi:10.1016/j. matlet.2016.05.041

Sanchez-Saez, S., Barbero, E., and Cirne, J. (2011). Experimental study of agglomerated-cork-cored structures subjected to ballistic impacts. Mater. Lett. 65, 2152-2154. doi:10.1016/j.matlet.2011.04.083

Shah, D. U., Schubel, P. J., and Clifford, M. J. (2013). Can flax replace E-glass in structural composites? A small wind turbine blade case study. Compos. B 52, 172-181. doi:10.1016/j.compositesb.2013.04.027

Tarlochan, F., and Ramesh, S. (2012). Composite sandwich structures with nested inserts for energy absorption application. Compos. Struct. 94, 904-916. doi:10.1016/j.compstruct.2011.10.010

Thornton, P. H. (1979). Energy absorption in composite structures. J. Compos. Mater. 13, 247-262. doi:10.1177/002199837901300308

Wambua, P., Ivens, J., and Verpoest, I. (2003). Natural fibres: can they replace glass in fibre reinforced plastics? Compos. Sci. Technol. 63, 1259-1264. doi:10.1016/ S0266-3538(03)00096-4

Wang, L., Fan, X. M., Chen, H., and Liu, W. Q. (2016). Axial crush behavior and energy absorption capability of foam-filled GFRP tubes under elevated and high temperature. Compos. Struct. 149, 339-350. doi:10.1016/j.compstruct. 2016.04.028
Yan, L., and Chouw, N. (2013). Crashworthiness characteristics of flax fibre reinforced epoxy tubes for energy absorption application. Mater. Des. 51, 629-640. doi:10.1016/j.matdes.2013.04.014

Yan, L., and Chouw, N. (2015). Effect of water, seawater and alkaline solution ageing on mechanical properties of flax fabric/epoxy composites used for civil engineering application. Construct. Build. Mater. 99, 118-127. doi:10.1016/j. conbuildmat.2015.09.025

Yan, L., Chouw, N., and Jayaraman, K. (2014a). Flax fibre and its composites a review. Compos. B 56, 296-317. doi:10.1016/j.compositesb.2013.08.014

Yan, L., Chouw, N., and Jayaraman, K. (2014b). Lateral crushing of empty and polyurethane-foam filled natural flax fabric reinforced epoxy composite tubes. Compos. B 63, 15-26. doi:10.1016/j.compositesb.2014.03.013

Yan, L., Chouw, N., and Jayaraman, K. (2014c). Effect of triggering and polyurethane foam-filler on axial crushing of natural flax/epoxy composite tubes. Mater. Des. 56, 528-541. doi:10.1016/j.matdes.2013.11.068

Yan, L., Su, S., and Chouw, N. (2015). Microstructure, flexural properties and durability of coir fibre reinforced concrete beams externally strengthened with flax FRP composites. Compos. B80,343-354.doi:10.1016/j.compositesb.2015.06.011

Zhou, H. Y., Attard, T. L., Dhiradhamvit, K., Wang, Y. L., and Erdman, D. (2015). Crashworthiness characteristics of a carbon fiber reinforced dual-phase epoxy-polyurea hybrid matrix composite. Compos. B 71, 17-27. doi:10.1016/j. compositesb.2014.10.053

Conflict of Interest Statement: The authors declare that the research was conducted in the absence of any commercial or financial relationships that could be construed as a potential conflict of interest.

Copyright (C) 2017 Yan, Wang and Kasal. This is an open-access article distributed under the terms of the Creative Commons Attribution License (CC BY). The use, distribution or reproduction in other forums is permitted, provided the original author(s) or licensor are credited and that the original publication in this journal is cited, in accordance with accepted academic practice. No use, distribution or reproduction is permitted which does not comply with these terms. 